\title{
INVESTIGACIÓN
}

Recibido: 23/02/2021--- Aceptado: 03/12/2021--- Publicado: 03/01/2022

\section{LOS PROFESIONALES DE LA INFORMACIÓN Y LAS FAKE NEWS DURANTE LA PANDEMIA DEL COVID-19}

\author{
Information professionals and fake news during the covid-19 pandemic
}

Aránzazu Román San Miguel: Universidad de Sevilla. España. arantxa@us.es

(8) Nuria Sánchez-Gey Valenzuela: Centro Universitario San Isidoro. España. nsanchezgey@centrosanisidoro.es

Rodrigo Elías Zambrano: Universidad de Sevilla. España.

rodrigoelias@us.es

Cómo citar el artículo:

Román San Miguel, A., Sánchez-Gey Valenzuela, N., y Elías Zambrano, R. (2022). Los profesionales de la información y las fake news durante la pandemia del covid19. Vivat Academia. Revista de Comunicación, 155, 131-149. http://doi.org/10.15178/va.2022.155.e1312

\section{RESUMEN}

Desde que en diciembre de 2019 comenzó a ser noticia en España el nuevo virus que provocaba la enfermedad denominada COVID-19, la población empezó a demandar más información. Ante esta situación, se expandió gran cantidad de informaciones falsas con las que el periodismo ha tenido que convivir, llegando incluso a colarse en las propias agendas mediáticas. Se parte de estas hipótesis: H1) Con la llegada de noticias sobre la COVID-19 aumentó el número de fake news en los medios televisivos, H2) El acceso a las fuentes de información cambió con el uso de plataformas de videollamada, no usadas hasta ahora de forma profesional para esta labor. Por tanto, en este trabajo se estudia qué papel han tenido los profesionales de la comunicación en esta pandemia y cuáles son las posibles causas del incremento de fake news. Para ello, se recogen los testimonios de periodistas, mediante muestreo aleatorio, que durante este periodo han trabajado en televisión desde Andalucía. La técnica utilizada ha sido el cuestionario a través de Google Docs, mezclando preguntas cerradas y abiertas relativas al acceso de los profesionales a las fuentes de información, los tiempos disponibles para contrastar datos, el volumen de publicaciones sin contrastar o sus posibles causas, entre otras. De las conclusiones destacan la constatación del aumento de la emisión de noticias falsas o sin contrastar, la variedad de causas que han motivado este fenómeno y la influencia positiva de las videollamadas para el acceso a las fuentes de información. 
PALABRAS CLAVE: Covid-19 - noticias falsas - periodismo - desinformación periodistas - videollamadas - televisión.

\begin{abstract}
Since the new virus causing the disease called COVID-19 made headlines in Spain in December 2019, the population has been demanding more information. Faced with this situation, a great deal of false information spread and journalism had to live with it, even slipping into the media's own agendas. We start from these hypotheses: H1) With the arrival of news about COVID-19, the number of fake news items in the television media increased, H2) Access to information sources changed with the use of video call platforms, not used until now in a professional way for this task. Therefore, this paper studies the role played by communication professionals in this pandemic and the possible causes of the increase in fake news. The methodology has focused on random sampling among professionals working in television in Andalusia during this period. The technique used was a questionnaire via Google Docs, mixing closed and open questions relating to the professionals' access to information sources, the time available to check data, the volume of unchecked publications or their possible causes, among others. Within the conclusions, it is worth noting the increase in the broadcasting of false or unverified news, the variety of causes that have led to this phenomenon and the positive influence of video calls on access to information sources.
\end{abstract}

KEYWORDS: COVID-19 - fake news - journalism - disinformation - journalists video calls - television.

\title{
OS PROFISSIONAIS DA INFORMAÇÃO E AS FAKE NEWS DURANTE A PANDEMIA DE COVID-19
}

\section{RESUMO}

Desde que o novo vírus causador da doença denominado COVID-19 começou a ser notícia na Espanha em dezembro de 2019, a população passou a demandar mais informações. Diante dessa situação, espalhou-se grande quantidade de informações falsas com as quais o jornalismo teve que conviver, chegando até a entrar furtivamente nas pautas dos próprios meios de comunicação. Partimos das seguintes hipóteses: H1) Com a chegada das notícias sobre o COVID-19, aumentou o número de notícias falsas na mídia televisiva, H2) $\mathrm{O}$ acesso às fontes de informação mudou com o uso de plataformas de videochamada, até então não utilizadas profissionalmente para este trabalho. Portanto, este trabalho estuda qual papel os profissionais de comunicação têm desempenhado nesta pandemia e quais são as possíveis causas do aumento de notícias falsas. Para isso, são recolhidos os testemunhos de jornalistas, por amostragem aleatória, que durante este período trabalharam na televisão andaluza. A técnica utilizada tem sido o questionário por meio do Google Docs, mesclando questões fechadas e abertas sobre o acesso dos profissionais às fontes de informação, os horários disponíveis para contrastar os dados, o volume de publicações não contratadas ou suas possíveis causas, entre

Vivat Academia. Revista de Comunicación., nº 155, 131-149. 
outros. As conclusões incluem a verificação do aumento da difusão de notícias falsas ou não contratadas, a variedade de causas que têm motivado este fenómeno e a influência positiva das videochamadas no acesso às fontes de informação.

PALAVRAS-CHAVE: Covid-19 - notícias falsas - jornalismo - desinformação jornalistas - videochamadas - televisão.

\section{INTRODUCCIÓN}

En épocas de crisis sanitarias aumenta el interés por la información y las noticias (Westlund y Ghersetti, 2015), una circunstancia que puede haber influido en el incremento del volumen de noticias publicadas durante la pandemia provocada por la COVID-19. De hecho, de todas las noticias publicadas en España desde el 9 de enero, cuando ya empezaba a hablarse de la expansión de un nuevo virus, hasta el 10 de abril de 2020, el 63,75\% son informaciones sobre éste (Lázaro-Rodríguez y Herrera-Viedma, 2020). La ciudadanía necesitaba información y se ha producido lo que la Organización Mundial de la Salud denomina "infodemia" (OMS, 2020), sobreabundancia de información sobre un asunto concreto, pero sin tener en cuenta si esta es rigurosa o no. La COVID-19 ha desencadenado la mayor fuente de rumores y de desinformación conocida (Larson, 2020). Una situación que ha derivado en una infoxicación o sobrecarga de información que impide profundizar en los temas (Niño-González, Barquero-Cabrero y García-García, 2017).

Para Salaverría (2018, p. 16), "en pocos años, hemos pasado de buscar noticias a sentirnos desbordados por la información". Internet ha cambiado las formas en que se reciben las noticias y también la cantidad de éstas que llegan a la ciudadanía. A pesar de existir plataformas para frenar las informaciones falsas a través de lo que se conoce como factchecking, con plataformas como Maldita o Newtral (VázquezHerrero y Vizoso y López-García, 2019), resulta realmente difícil frenar la cantidad de bulos que llegan a los receptores. La democratización de la desinformación es ya una realidad, cualquier persona puede crear informaciones falsas que, aparentemente, pueden resultar verosímiles, y difundirlas a gran velocidad sin que ello suponga asumir responsabilidades por parte de quienes las difunden, teniendo que rectificar a veces, pero siempre después de que el daño ya esté hecho (Kim y Moravec y Dennis, 2017).

Ante este aumento de información, los profesionales del periodismo juegan un papel clave para corregir la desinformación existente, ya que las fake news han llegado a colarse en las agendas de los medios tradicionales durante la pandemia (Román, Sánchez y Elías, 2020). Una de las maneras de paliar estas situaciones es priorizando la información de calidad, entendiendo ésta también como información veraz, que permite a los ciudadanos tener una opinión formada y por tanto crítica, que es uno de los objetivos principales del periodismo (Kovach y Rosenstiel, 2007). Por ello, es necesario que los ciudadanos tengan acceso a la información (Habermas, 2006), pero no a cualquier tipo de información. Los periodistas podrán paliar estos bulos si son capaces de filtrar la información veraz y poner a disposición de la población recursos de calidad contrastada (Aleixandre-Benavent, Castelló-Cogollos y Valderrama-

Vivat Academia. Revista de Comunicación., n 155, 131-149. 
Zurián, 2020). Una empresa difícil en otros ámbitos como son las redes sociales o aplicaciones como WhatsApp, aunque estas mismas plataformas pueden contribuir al contraste de información mediante los sistemas de verificación (Bernal-Triviño y Clares-Gavilán, 2019).

El fenómeno de las fake news no podemos pensar que es algo nuevo, sino que hace años que se viene estudiando (Parra y Oliveira, 2018, Blanco-Herrero y ArcilaCalderón, 2019), ya que afectan gravemente a la información falseando la realidad que recibe la ciudadanía a través de diferentes canales, sobre todo las redes sociales (Silverio, 2018 y Shu et al., 2017). En este contexto, la televisión juega un papel fundamental. La televisión fue el medio más utilizado por los españoles para informarse sobre el coronavirus, según los datos que publicó la página web estatista.com (2020). Este medio fue utilizado por el $85 \%$ de la población; la prensa, por su parte, solo fue elegida por el $54 \%$ de las personas que quería saber sobre la situación y el $53 \%$ de la ciudadanía recurrió a las fuentes oficiales. Curiosamente, solo el 38\% de quienes se informaron sobre el virus lo hicieron a través de las redes sociales. Y es que, cuando se dan situaciones complejas o que la población considera relevantes la televisión es la preferida de los españoles, así lo reflejaron también los datos del CIS en la 25 conferencia de la ONU sobre el cambio climático (CIS, 2020).

Estudios recientes sobre la pandemia llegan a la misma conclusión. Así, Masip, AranRamspott, Ruiz-Caballero, Suau, Almenar y Puertas Graell (2020), a pesar de que afirman que los medios digitales fueron los mayormente elegidos como primera opción por la población para informarse y tras ellos los informativos de televisión (38,9\% y 33,9\% respectivamente), consideran que, si se suman los porcentajes de personas que eligieron cada uno de los medios como primera, segunda y tercera opción, los españoles prefirieron la televisión. Unas conclusiones similares a las obtenidas en un estudio sobre la gestión de la comunicación durante la pandemia por la COVID-19 en España realizado por Moreno, Fuentes-Lara y Navarro (2020).

\subsection{El papel de los profesionales de la información.}

Las redes sociales han venido a revolucionar las formas en las que trabajan los profesionales de la información. Si Internet vino a romper con el monopolio que poseían los medios de comunicación en la difusión de información (Casero-Ripollés y López-Meri, 2015), las redes sociales, su incidencia y proliferación han provocado mala praxis periodística en muchos casos, utilizando noticias directamente inventadas, titulares que llevan a la confusión, noticias que carecen de sentido y otras técnicas para conseguir la tan ansiada viralidad y aumentar el número de visitas y el tráfico en los medios digitales. Por tanto, se ha producido un aumento de fake news y prácticas como el clickbait, que consiste en publicar titulares gancho que faltan a la verdad y atentan contra los valores propios del periodismo, eliminado la prioridad informativa y elevando la económica; todo ello para conseguir audiencia en los medios digitales (López-Borrull, Vives-Gràcia y Badell, 2018; Bazaco, Redondo y Sánchez-García, 2019; Molyneux y Coddington, 2019; Zannettou et al. 2019). 
Si, como afirman López-Borrull, Vives-Gràcia y Badell "las noticias falsas han venido para quedarse" (2018, p. 1.354), los profesionales de la información tendrán que trabajar en la formación de los usuarios y en la validación de las fuentes, y en momentos como el que está viviendo el mundo actual, los periodistas deberán hacer un esfuerzo aún mayor por doblegar esta tendencia.

La importancia del periodismo en momentos de crisis, y la pandemia lo es, resulta fundamental. De hecho, organismos que tanto tienen que decir sobre asuntos de esta magnitud como la Organización Mundial de la Salud (OMS), han mostrado su preocupación por la desinformación respecto a la COVID-19. En este sentido, la OMS publicó un policy brief llamado 'Desinfodemia'. Descifrando la desinformación sobre el COVID-19' escrito por la Directora Global de Investigación del Centro Internacional de Periodistas (ICJF), Julie Posetti y la profesora Kalina Bontcheva, miembro del Centro para la Libertad de los Medios de Comunicación, en adelante ICFJ, (2020). En este informe, las autoras diferencian entre lo que se llama desinformación o 'desinfodemia', por ejemplo "la producción de contenidos prometiendo tratamientos falsos con el objetivo de alcanzar ganancias privadas" (p.2), y la información errónea o misinformation, que se produce cuando se comparte información falsa de forma inconsciente, pensando que es verdadera, con la intención real de ayudar.

Hasta tal punto ha llegado la importancia de parar la desinformación, que el ICFJ lanzó el Foro Mundial de Reportaje sobre la Crisis Sanitaria mundial donde se incluye "un centro interactivo y multilingüe para que miles de periodistas alrededor del mundo puedan apoyar el reportaje ético e informado mediante el acceso directo a fuentes confiables de experticia científica y médica; facilitar el intercambio de conocimientos y la verificación/desmitificación colaborativas con referencia a la COVID-19" (Posetti y Bontcheva, 2020, p. 13). Además, se han hecho esfuerzos desde diversas organizaciones para la alfabetización mediática de diferentes colectivos, entre ellos los periodistas: traducciones de la UNESCO a diferentes idiomas de su manual 'Periodismo, Noticias falsas y desinformación' a través del crowdsourcing; FistDraft creó una página con una 'base de datos verificados' donde se puede encontrar una lista de fuentes fiables sobre la pandemia; webinarios educativos con reportajes sobre este tema y guías de ayuda para verificar y desmentir información sobre la COVID-19; una "lista curada de recursos, herramientas, sugerencias y fuentes vinculadas con los reportajes sobre el COVID-19, incluyendo una colección sobre la verificación de los hechos" creada por el Centro Africano de Excelencia Mediática (ACME); entre otros (Posetti y Bontcheva, 2020, p. 13).

Tan en serio se han tomado diferentes organismos internacionales los peligros de la desinformación durante la pandemia, que se organizó el 4 de mayo de 2020 un curso abierto en línea (MOOC) titulado: "Periodismo en la pandemia: Cubrir el COVID-19 ahora y en el futuro". El curso fue organizado por la Unesco, la Organización Mundial de la Salud (OMS) y el Centro Knight de Periodismo en las Américas de la Universidad de Texas. En él, diferentes profesionales de la información debatieron y reflexionaron sobre la importancia de verificar toda la información que se estaba 
produciendo sobre la pandemia y cómo cubrir de una forma más profesional este acontecimiento de repercusión mundial.

\section{OBJETIVOS}

Esta investigación parte de la hipótesis principal de que, con la llegada de noticias sobre la COVID-19, aumentó el número de fake news difundidas por los profesionales de la comunicación que trabajan en televisión en Andalucía, y pretende estudiar sus posibles causas. Una segunda hipótesis que también se plantea sostiene que el acceso a las fuentes de información cambió debido a las circunstancias sanitarias, obligando a los medios a hacer uso de plataformas de videollamada, hasta ahora no usadas habitualmente de forma profesional para la labor informativa.

Así, el objetivo principal de este trabajo radica en conocer la opinión de los profesionales de los medios televisivos que trabajan en Andalucía sobre sus condiciones de trabajo en este año 2020 marcado por la pandemia, antes, durante y tras el confinamiento, y cómo creen que la situación afectó a que pudieran proliferar las fake news durante este periodo.

\section{METODOLOGÍA}

Para conseguir este objetivo, se ha utilizado un cuestionario con muestreo aleatorio a través de un formulario de Google Docs, donde se han mezclado preguntas cerradas con otras abiertas, enviado a periodistas de televisión que trabajan en diferentes medios en Andalucía: Canal Sur Televisión, Televisión Española, Telecinco, Antena 3, Cuatro, La Sexta, Europa Press Televisión, y EFE Televisión. A estos profesionales se les ha pedido que lo difundan entre sus contactos dentro del gremio y se han sumado también periodistas de Telemadrid o de Trece TV, del grupo de comunicación Veo Tv.

\section{RESULTADOS}

En esta investigación han participado 18 profesionales que trabajan en televisión en Andalucía. El 72,2\% de los encuestados es mujer frente al 27,8\% de hombres.

La cadena de televisión más representada en este estudio, a través del testimonio de sus trabajadores, es la televisión autonómica pública andaluza, Canal Sur Televisión, con un $28 \%$. Del resto de cadenas la representación es más o menos igualitaria, a excepción de Europa Press Tv con una representación muy baja, y La Sexta y Cuatro, de las que finalmente no se obtuvieron respuestas. 


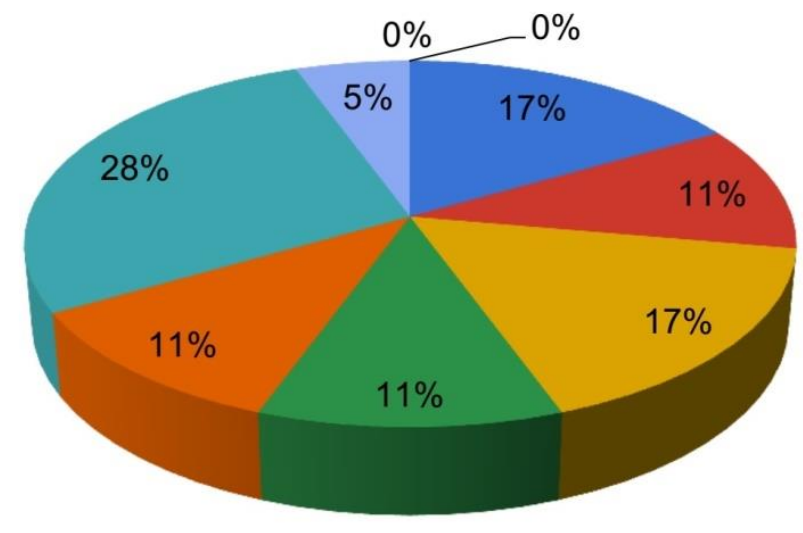

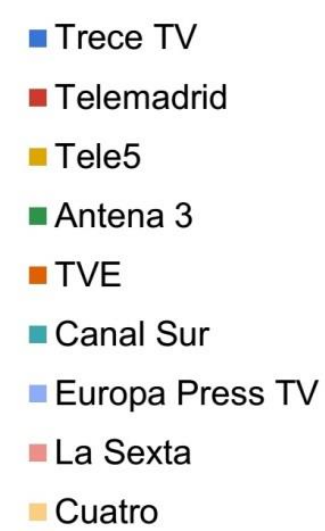

Figura 1. Medios en los que trabajan los encuestados.

Fuente: Elaboración propia.

Los requisitos que se solicitaban para poder participar en esta investigación es que los encuestados fueran periodistas que trabajaran para alguna televisión en Andalucía y que hubieran estado en activo durante la pandemia provocada por el coronavirus. Un dato relevante es que en un país donde se decretó un Estado de Alarma, que hizo que solo los trabajadores de servicios considerados esenciales siguieran ejerciendo, el 94,4\% de los preguntados asegura que no dejó de trabajar ni siquiera durante el confinamiento obligatorio.

Cierto es que el ejecutivo determinó desde el primer momento que los medios de comunicación "son un servicio esencial, sin distinción," (García, 2020). ¿Y qué consecuencias ha tenido para estos profesionales seguir trabajando en las condiciones impuestas por la pandemia? Según los encuestados las primeras modificaciones tuvieron que ver con el lugar de trabajo. Muchos de ellos pasaron a realizar a través de teletrabajo las funciones que hacían antes de la pandemia en redacción: "Dejamos de pisar la oficina, tuvimos que teletrabajar y adaptar nuestra propia casa a las necesidades del trabajo. Trabajar con niños pequeños en casa no es fácil", explican. Estos cambios se pueden considerar más generales y no específicos del trabajo periodístico, sin embargo, hay otros que sí.

Trabajar durante el confinamiento también supuso exponerse más a ser contagiado durante la jornada laboral. "El problema era la exposición constante, al tener que seguir trabajando, a veces con poca seguridad", explican. No obstante, aseguran que hubo un tiempo en el que se eliminaron las entrevistas presenciales para evitar la cercanía con otras personas y se normalizó el uso de los micrófonos con pértiga que te permiten no tener que acércate a los entrevistados. Y no solo eso. Hubo empresas que tomaron medidas ante la exposición de los periodistas a la hora de realizar su trabajo: "La empresa para la que trabajo, por ejemplo, decidió doblar equipos para que estuviésemos menos expuestos en la calle. Los compañeros y yo pasamos a trabajar tres días a la semana." 
Se establecieron cambios técnicos y también de plantilla, pero no fueron los únicos. Los periodistas mantienen que también se produjeron modificaciones en lo que se refiere al contenido. Había más trabajo, se llenaban más horas de televisión, pero había menos actos, menos eventos programados, se redujeron las coberturas fijadas, por lo que un lado positivo que destacan es que aumentó la creatividad. "Al haber menos agendas y convocatorias fue necesario 'buscarse la vida' para poder sacar los días adelante". Se refieren a buscar temas novedosos y medios técnicos no utilizados antes para poder rellenar las escaletas y las parrillas de las cadenas. "A la hora de hacer reportajes hubo que innovar para poder sacar el trabajo adelante. Un trabajo, sobre todo, apoyado en videollamadas, pero también en vídeos que se grababan los propios protagonistas."

\subsection{Las fuentes de información}

Para los periodistas es fundamental en su trabajo acceder a las fuentes de información adecuadas ya que esto determinará el resultado de su labor y a la vez la función social que cumplen con esta (Sánchez-Gey, 2021).

No obstante, en el desarrollo de la función periodística durante la pandemia provocada por el COVID-19, los profesionales que participan en esta investigación mantienen en un 55,6\% que tuvieron las mismas fuentes que antes y solo un $27,8 \%$ asegura que el número de fuentes se vio disminuido. Por tanto, el $72,3 \%$ de los encuestados consideran que las fuentes o se han mantenido o se han incrementado.

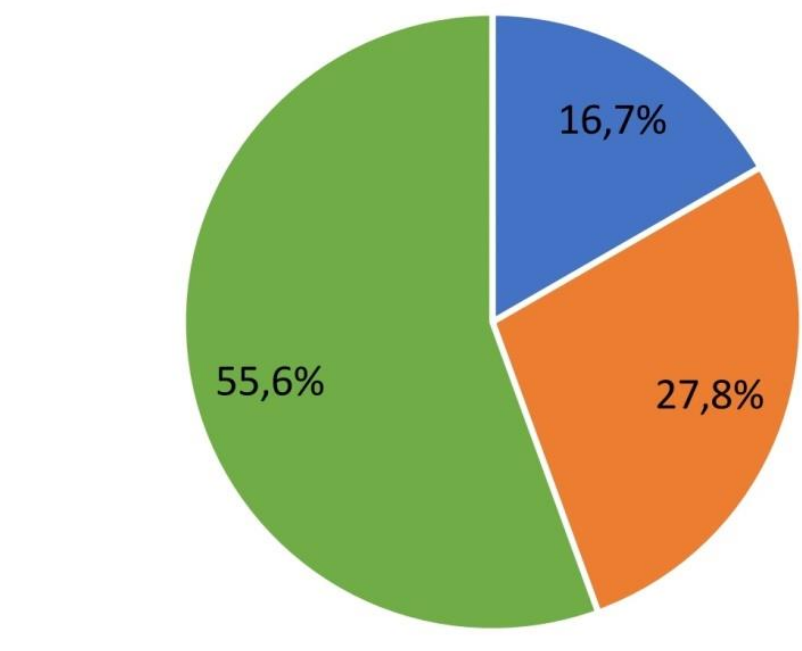

- Más que antes - Menos que antes - Igual que antes

Figura 2. Comparación del número de fuentes que pudieron consultar respecto a antes de la pandemia.

Fuente: Elaboración propia.

Los periodistas afirman que el uso de nuevos medios tecnológicos -sobre todo las nuevas plataformas de videollamadas online- han sido esenciales para que esta

Vivat Academia. Revista de Comunicación., nº 155, 131-149. 
circunstancia, es decir la no disminución de fuentes de información, se produjera. Herramientas como Skype, Zoom, WhatsApp u otras similares han hecho que, aunque se limitara el contacto entre los periodistas y las fuentes en el día a día, no se notara esta carencia en la realización de su trabajo. Así lo confirma el hecho de que el $94,4 \%$ de los encuestados asegure que las videollamadas ayudaron a que hubiera más fuentes de información disponibles.

No obstante, entre los que consideran que ha habido menos fuentes que antes de la pandemia encontramos este testimonio: "Desde el punto de vista del comunicador está siendo más complicado contrastar, muchas fuentes se excusan en la pandemia para no ofrecer la información requerida. Un ejemplo, la información sobre la situación sanitaria sólo proviene de fuentes oficiales y apenas se pueden contrastar. Por tanto, te tienes que fiar de que no hay intereses detrás de estos datos," concluye. Asimismo, aseguran que recibieron informaciones contradictorias por parte de las administraciones que también ha podido facilitar la propagación de algunos bulos. “Bajo mi punto de vista, la pandemia ha podido cambiar la forma de trabajar, pero nunca el fin; informar con rigor y objetividad".

\subsection{El desarrollo de las fake news durante la pandemia}

Es una realidad que la COVID-19 ha desencadenado la mayor fuente de rumores y de desinformación conocida (Larson, 2020). Pero los profesionales que ejercen el periodismo tienen una visión muy concreta sobre este hecho. Ante la pregunta de si publicaron datos que posteriormente resultaron ser falsos o fueron desmentidos, el $83,3 \%$ de los encuestados asegura que no, no obstante, resulta importante hacer alusión al 11,1\% que no quiere contestar a esta pregunta.

Sin embargo, cuando se les pregunta si consideran que durante la pandemia se han dado más informaciones falsas o poco contrastadas que en otros momentos, hasta un $61,1 \%$ mantiene que se han dado más, algo que contrastaría con la repuesta anterior.

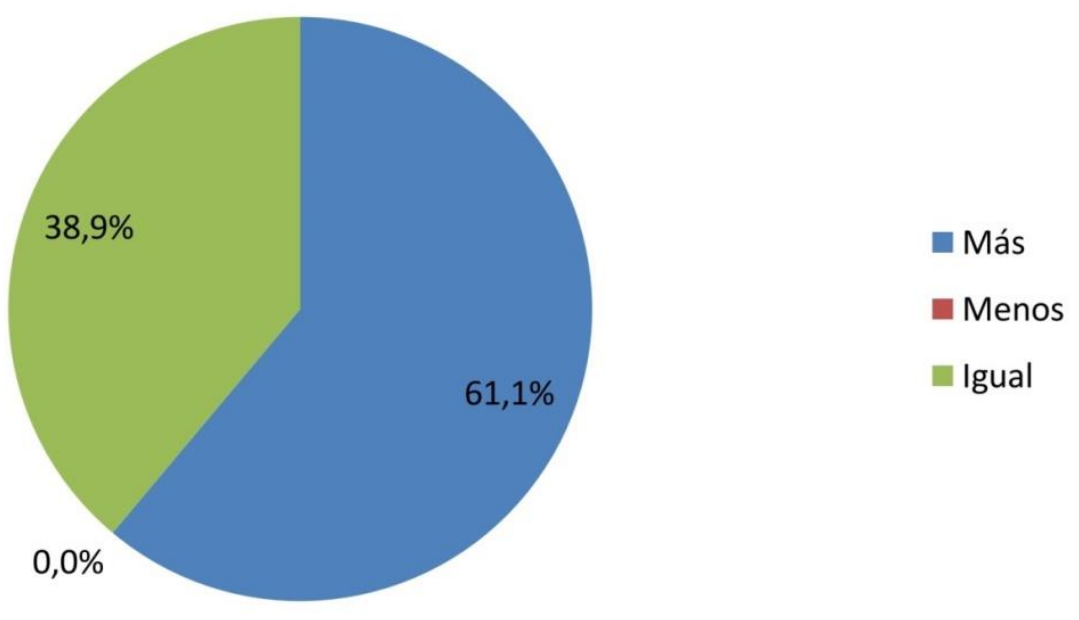

Figura 3. Respuestas sobre si se publicaron más noticias falsas o poco contrastadas.

Fuente: Elaboración propia. 
Sobre los motivos que consideran como causas de este aumento de bulos o fake news mantienen que es una tendencia propia de los momentos de incertidumbre. Aseguran que uno de los problemas es el aumento de información, la 'infodemia', que se produce en este tipo de crisis: "Había demasiado caudal de información y poco tiempo para procesarla", dicen. La velocidad es otro de los argumentos que los periodistas suelen esgrimir como uno de los peores problemas del periodismo actual en relación a alcanzar la calidad periodística necesaria (Sánchez-Gey, 2019). “Una de las razones está en la falta de información, especialmente al principio. La velocidad a la que todo sucedió también influye, no había casi tiempo para lo que siempre hay que hacer, contrastar."

Los encuestados también vinculan las redes sociales con este aumento de informaciones falsas: "Las redes sociales han tenido un papel determinante. Había más cantidad de información en las redes sociales, y esto unido al miedo y, al mismo tiempo, al desconocimiento ante una situación totalmente nueva provocó el aumento de estos bulos." Aquí se menciona también el desconocimiento que había de todo lo que estaba pasando y, en concreto, del nuevo virus.

Los profesionales señalan otro factor más en relación a las fake news durante la pandemia y es la motivación política. "Los grupos de presión aprovechan esta situación excepcional para sembrar su semilla y sacar rédito. La población ha necesitado más que nunca estar informada y por eso utilizan los medios", explica.

No obstante, hay quien defiende que, a pesar de este aumento, los profesionales tenían herramientas para no caer en estas fake news: "Creo y quiero pensar que todos intentamos dar información contrastada antes y durante el confinamiento. Creo que la información ha sido la misma, sigue dependiendo de la calidad del profesional que la dé y de la autonomía y el rigor del medio donde trabaje."

Esta respuesta más idílica del periodismo, como sostén de la función social que defiende el derecho recogido en el artículo 20 de la Constitución Española (1978) a dar y recibir información veraz a través de los medios de comunicación, se confirma en el hecho de que un 72,2\% asegura que los medios de comunicación no incluyen noticias falsas conscientemente. Pero, atendiendo a la ética profesional, el hecho de que una persona haya contestado que sí introduce bulos sabiendo que lo son, resulta del todo reprobable. 


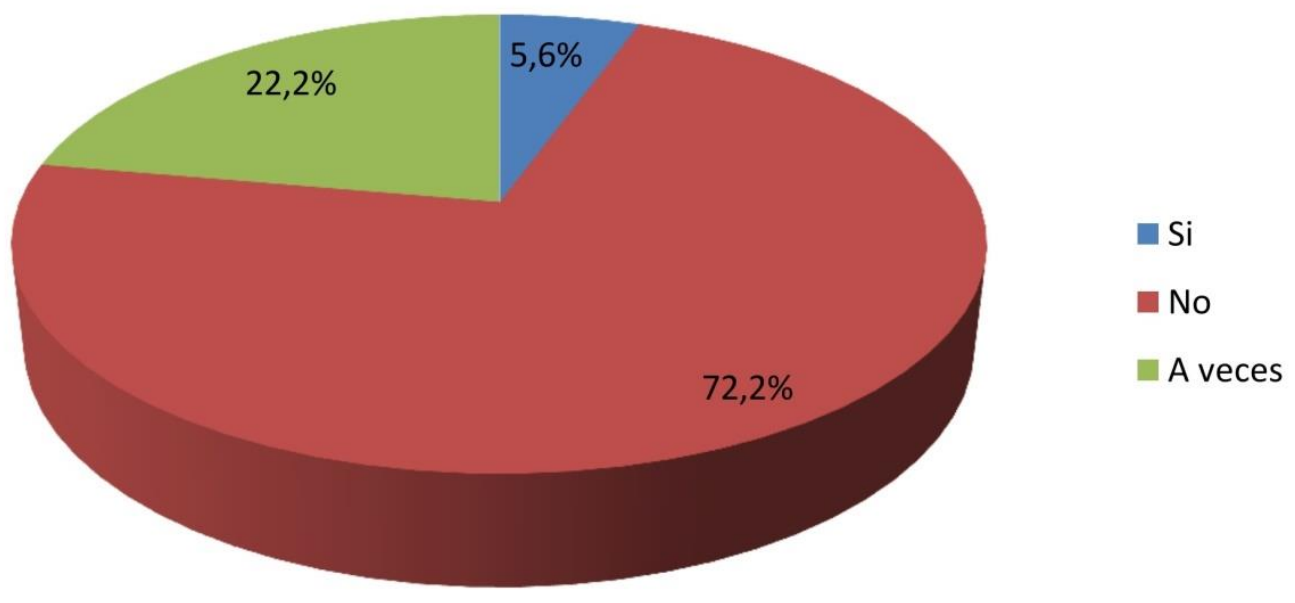

Figura 4. Respuestas sobre si los medios dan noticias falsas conscientemente.

Fuente: Elaboración propia.

Por fortuna, una gran mayoría considera que no se incluyen bulos sabiéndolo, pero el $22,2 \%$ dice que a veces sí se cuentan fake news siendo conscientes los profesionales de ello. Los motivos que esgrimen para esta práctica son variados, por un lado, aluden a la línea editorial, otra motivación la encuentran en los ideales políticos, utilizando los medios como altavoz de informaciones falsas para recabar adeptos para un partido en concreto: "Quieren decirle a su público lo que quieren escuchar, aunque sea falso." Pero van más allá. Mantienen que es un proceso más sofisticado que el simple hecho de introducir un bulo que circula por Internet en la agenda del medio: "no se trata de noticias falsas íntegramente, sino que se ofrece la información de forma sesgada omitiendo los datos que no interesan o exagerando otros. Principalmente porque hay presiones políticas directas a los medios, también las empresas accionistas del grupo, anunciantes..." Varios de los preguntados mantienen que el control político y la politización de los medios ha sido descarada durante la pandemia. Algo que desde el punto de vista de la economía política de la información señalan varios autores:

Si los medios nos ocultan las cuestiones negativas sobre su propia empresa, eso quiere decir que tienen asumido el hecho de ponerse al servicio de criterios no profesionales, que harán lo mismo con noticias o informaciones negativas referentes a los Gobiernos o políticos de su confianza y que magnificarán los escándalos de sus enemigos. (Serrano, 2010, p.20 y 21)

A la misma conclusión llegan Reig y Labio (2017, p.43) al mantener que "las propias empresas de comunicación se relacionan de manera directa o indirecta con otras que poseen múltiples intereses a partir de lo que denominamos 'conecting doors', término que acuñamos en un artículo periodístico para explicar un escalón superior a lo que se conocen como puertas giratorias."

No obstante, los encuestados se defienden: “A pesar de la manipulación de ciertas informaciones por parte de los grandes grupos, puedo asegurar que la integridad, los 
valores y la responsabilidad de la mayoría de los informadores a pie de calle sigue intacta. Yo a día de hoy puedo seguir durmiendo tranquila porque nunca me he visto en la obligación de contar algo que no sea cierto y he conseguido "tirar" temas de la escaleta del informativo que no se ajustaban a la realidad", explica con orgullo.

Por último, encontramos la postura idealista de "quiero creer que no los hacen" o "tengo fe en que no", junto a la postura de que mantiene que si un medio incluye informaciones falsas conscientemente debería ser sancionado por ello.

Es más, cuando se pregunta sobre el medio concreto en el que trabajan como periodistas las respuestas son más corporativistas o más evasivas. Desde el que niega que en su medio se den, los que aseguran que prefieren no responder a esa cuestión (habiendo contestado las otras), pero también quienes ponen ejemplos concretos porque son conocedoras de que es una tendencia que actualmente se da en los medios de comunicación, incluso los más tradicionales (Román-San Miguel, SánchezGey y Elías, 2020). “Cuando el Gobierno aprobó la última ley anti desahucios, en el medio en el que trabajo se pasó por alto contar, o apenas nombraron, que se prohíban los desahucios salvo que el propietario tuviera más de diez inmuebles. Un dato fundamental para entender que detrás de ese desalojo no hay un ciudadano de a pie amargado por un okupa, sino un fondo buitre o un banco sin problema habitacional." No es el único ejemplo dado por los encuestados: "También se hizo mucho hincapié en el desfase entre los datos de fallecidos por coronavirus aportados por el Gobierno y por otras fuentes, me parece que está bien contarlo, pero no mostrarlo constantemente como si el ejecutivo nos estuviera ocultando la realidad. Los intereses políticos y económicos de los grupos de comunicación no son ningún secreto".

\subsection{El papel de los periodistas frente a la COVID-19}

Los profesionales de la información que han participado en este trabajo de investigación consideran en un $77,8 \%$ que el periodismo ha sido y es fundamental, crucial, indispensable, en el momento actual. Tras ser preguntados sobre el papel de los medios durante esta pandemia, los encuestados aseguran que han informado, acompañado y entretenido. Consideran que el papel de los medios es "el mismo de siempre. Informar de la actualidad. Las malas noticias siempre son noticia y durante el confinamiento y la pandemia más que nunca, por desgracia", explican. Convirtiéndose en imprescindibles: "para la mayoría de las personas, esta era la única ventana a la realidad y a la situación excepcional que se estaba viviendo."

También incluyen el cometido de los medios como generadores de opinión. "El periodismo, la información, ayuda a crear opinión, por eso es necesario contrastar, leer varios medios con la pandemia o sin ella, es fundamental para estar informado. $Y$ en este momento la sociedad demandaba información sobre lo que estaba ocurriendo y si no hubiera estado informada la desinformación sería alarmante."

Además, no se olvidan de señalar la función de servicio público que la Constitución Española (1978) encomienda a los medios de comunicación: "Han tenido un 
importante papel educativo para la población. Se han explicado todas las formas posibles de transmisión, de prevención, los tipos de test, los efectos económicos, la situación sanitaria, el tipo de vacunas... Esta fotografía proporcionada por los medios ha facilitado que la población encaje mejor todas las medidas restrictivas. Sin esta información diaria sobre los contagiados o los fallecidos, por ejemplo, no se hubiera entendido la gravedad y se habrían producido muchas más actitudes irresponsables." Una tarea además de mucha responsabilidad. "Se han cumplido las funciones clásicas y la de orientar a las personas para saber cómo enfrentarse al día a día, informando a la población casi minuto a minuto."

Del mismo modo, los profesionales destacan el papel pedagógico que desempeñaron los medios en este periodo: "no solo han servido para arrojar luz sobre lo que estaba sucediendo mientras se estaba encerrado entre cuatro paredes, también han tenido un papel didáctico muy importante." Gracias a esto los ciudadanos pudieron conocer las medidas restrictivas, cuándo entraban en vigor, el número de casos, la situación de los hospitales... "La gente normalmente no lee el BOE ni consulta los PDF que cuelgan las Consejerías en sus páginas web ni conoce la realidad de lo que ocurre más allá de su barrio. Han sido los medios los que han 'traducido' los datos, han machacado las medidas de responsabilidad, les han mostrado la gravedad de la situación en todo el mundo, han enseñado la realidad de muchas familias, las dificultades de tantos sectores".

No obstante, reconocen que también se ha producido una saturación de información incluso el hastío de la gente.

Asimismo, hay quien es más crítico considerando que el papel de los medios se ha visto reducido, ya que aseguran que se ha visto totalmente politizado "de mero transmisor." "La audiencia, la población, ha vivido esta crisis sanitaria encerrada en casa, pegada a la televisión para informarse de cualquier novedad. Considero que el periodismo, y en concreto la televisión, ha tenido un papel fundamental trasladando en tiempo real las decisiones de nuestros mandatarios y la situación que se ha vivido en los hospitales y además ha sido motor de concienciación para que la sociedad fuera consciente de la realidad que se vivía en España y en el mundo."

Por ello aseguran que el papel de los medios y los profesionales que trabajan en ellos ha sido muy importante, aunque quizá mejorable, matizando que que, a pesar de la importancia que consideran que tiene su labor, la sociedad no la valora. "A los periodistas se nos ha valorado poco nuestro trabajo. No digo que hayamos sido superhéroes como los sanitarios, pero estábamos donde estaba la noticia a pesar del riesgo de contagiarnos", aseguran. "Se han cometido errores, sí, pero en parte, quiero pensar que se debe a la velocidad a la que todo ha sucedido."

Por otra parte, los profesionales preguntados han analizado su papel individual, concreto, como periodistas. "Mi papel no ha cambiado. Por mucho que cambie un entorno, la función del periodista sigue siendo la de informar con rigor y veracidad, y así he intentado hacerlo. He intentado contrastar siempre mucho lo que decían los 
datos oficiales porque en muchas ocasiones estaban desfasados y cuando nos los daban ya no correspondían con la realidad en ese momento."

También han destacado el cambio que han tenido que afrontar en la manera de contar lo que sucedía por las características especiales de esta pandemia. "He intentado buscar testimonios de la nueva realidad que estábamos viviendo. Historias que han marcado estos meses: sanitarios desbordados, familias separadas, abuelos en soledad... Los nuevos protagonistas de una situación hasta ahora nueva para todos." Es decir, ponerles cara a los datos: "Encontrar ejemplos de personas que hayan tenido que cerrar sus negocios, personas que han perdido algún familiar, familias que tienen que recurrir a la caridad para salir adelante... En ese sentido me he sentido satisfecha porque creo que es fundamental dar voz a quien lo necesita, sin caer en el sensacionalismo." No obstante, concluyen que: "Me hubiera gustado poder contar mejor la saturación de la sanidad y las muertes, pero acceder era imposible debido las circunstancias."

Dentro de esta función sí confiesan que en algunos momentos (sobre todo al principio) se consideró que el enfoque debía ser positivo y tranquilizador, "dando pautas especialmente a las personas mayores de cómo debían actuar en cada escenario que se les estaba presentando durante la pandemia". No obstante, sin incurrir en desvirtuar la información de lo que estaba ocurriendo: "He tratado de informar de manera honesta, intentando no caer en el alarmismo que a veces se observa. He contado lo malo, porque ahí está, pero también lo bueno y los datos positivos cuando los hemos tenido. Por lo que el entretenimiento y la búsqueda de temas alegres ha sido otro de los grandes retos durante estos meses de crisis sanitaria."

\section{DISCUSIÓN Y CONCLUSIONES}

Esta investigación partía de la hipótesis principal de que, con la llegada de noticias sobre la COVID-19, aumentó el número de fake news emitidas en los medios televisivos. A la luz de los resultados expuestos, podemos afirmar que dicha afirmación queda contrastada en base a la opinión de los profesionales consultados que realizan su labor en Andalucía. Sobre las causas de dicho fenómeno, los resultados destacan un conjunto de motivos variados cuya influencia se reparte en proporciones parecidas, donde destacan la falta de información facilitada por parte de las instituciones públicas (sobre todo al inicio del Estado de alarma), la incertidumbre y el desconocimiento ante una situación desconocida, el exceso de información que circulaba a través de las redes sociales, la escasez de tiempo dado a los periodistas para contrastar las informaciones recibidas o los intereses políticos.

La segunda hipótesis que también se planteaba sostenía que, con motivo de las excepcionales circunstancias sanitarias motivadas por la pandemia de la COVID-19 en 2020, se produjo un cambio de acceso a las fuentes de información, ya que el contacto físico tradicional de las entrevistas realizadas in situ dejó paso en numerosas ocasiones a la utilización de plataformas de videollamada hasta ahora usadas solamente de forma muy excepcional para la labor informativa. Sobre este aspecto,

Vivat Academia. Revista de Comunicación., n 155, 131-149. 
los resultados de la investigación también constatan dicha hipótesis, ya que los profesionales encuestados afirmaron que sufrieron dicho cambio en sus medios de comunicación. Además, podemos destacar que una amplia mayoría de los profesionales que han respondido al cuestionario (el 72,3\%) consideraron que su acceso a las fuentes no se vio afectado negativamente en este periodo, sino que se mantuvo igual o incluso incrementó sus posibilidades de recabar información de los protagonistas sobre la actualidad de la pandemia. De manera casi unánime (todos excepto uno), los resultados muestran que el uso de dichas videollamadas proporcionó una mayor facilidad para acceder a entrevistas a cambio de sacrificar la presencia física en el lugar de la noticia.

Podemos señalar además el reconocimiento por parte de la mayoría de los encuestados $(61,1 \%)$ de que en los medios de comunicación se publicaron informaciones falsas o sin contrastar correctamente durante el periodo analizado, si bien niegan de forma abrumadora $(83,33 \%)$ que eso haya ocurrido en sus propias noticias y medios. Estas afirmaciones, que pueden interpretarse como contradictorias, pueden deberse a una posible falta de autocrítica o bien a cierto recelo a criticar a sus propios medios.

Donde sí existe consenso entre los periodistas que trabajan en Andalucía, es en la importancia fundamental de los medios periodísticos en un momento de pandemia como la actual, destacando su labor de servicio público tanto desde el punto de vista informativo, como formativo/educativo. Entre las labores informativas desarrolladas subrayan aspectos de enorme interés como los datos difundidos sobre el número de personas contagiadas, la situación de los hospitales, las medidas restrictivas o la transmisión de información de publicaciones oficiales como el BOE, que la ciudadanía difícilmente consulta y que los medios facilitan de manera más accesible. Dentro de su labor formativa, según los resultados obtenidos destacan el uso educativo de la televisión para instruir respecto a formas de transmisión del virus, medidas para evitar contagios, tipos de test y vacunas o la concienciación social de la población en general.

Ante un fenómeno novedoso y de enorme importancia tanto social como informativa, como es la pandemia causada por la COVID-19 en España, en el presente artículo se ha pretendido analizar un aspecto de gran trascendencia como el aumento de noticias falsas o sin contrastar en medios televisivos durante el año 2020, a través de los profesionales que trabajan en la comunidad andaluza. La variedad en la recogida de datos, facilitados por profesionales pertenecientes a 7 medios diferentes y de distinto tipo, públicos y privados, nacionales y autonómicos, e incluso agencias de noticias, aporta una importante pluralidad de puntos de vista sobre la situación, enriqueciendo así el valor de la muestra. La influencia del demostrado aumento de fake news emitidas durante el periodo analizado puede interpretarse como un peligro para la información de la ciudadanía y el normal desarrollo democrático de nuestro país, lo que supone una interesante línea de investigación para continuar en el futuro. 


\section{REFERENCIAS}

Aleixandre-Benavent, R., Castelló-Cogollos, L. y Alderrama-Zurián, J. C. (2020). Información y comunicación durante los primeros meses de Covid-19. Infodemia, desinformación y papel de los profesionales de la información. Profesional de la información, 29(4). https://doi.org/10.3145/epi.2020.jul.08

Bazaco, A., Redondo, M. \& Sánchez-García, P. (2019). Clickbait as a strategy of viral journalism: conceptualisation and methods. Revista Latina de Comunicación Social, 74, 94-115. https:// doi.org/10.4185/RLCS-2018-1323en

Blanco-Herrero, D. y Arcila-Calderón, C. (2019): “Deontología y noticias falsas: estudio de las percepciones de periodistas españoles". El profesional de la información 28(3), 1-13. https://doi.org/10.3145/epi.2019.may.08

Bernal-Triviño, A. y Clares-Gavilán, J. (2019). Uso del móvil y las redes sociales como canales de verificación de fake news. El caso de Maldita.es. El profesional de la información, 28(3), 1-8. https://doi.org/10.3145/epi.2019.may.12

Casero-Ripollés, A. (2020). Impact of Covid-19 on the media system. Communicative and democratic consequences of news consumption during the outbreak. El profesional de la información, 29(2). https://doi.org/10.3145/epi.2020.mar.23

Casero-Riupollés, A. y López-Meri, A. (2015) Redes sociales, periodismo de datos y democracia monitorizada. En F. Campos y J. Rúas (eds.). Las redes sociales digitales en el ecosistema mediático. Sociedad Latina de Comunicación Social, 96113.

Constitución Española, 1978. Artículo no 20. Congreso de Diputados. http://bit.ly/37XGFKe

García, L. B. (2020, 28 de marzo). El Gobierno obliga a quedarse en casa a los trabajadores de servicios no esenciales del 30 de marzo al 9 de abril. La Vanguardia. http://bit.ly/3oGvMSH

Habermas, J. (2006). Political communication in media society: Does democracy still enjoy an epistemic dimension? The impact of normative theory on empirical research. Communication theory, 16 (4), pp. 411-426. https://doi.org/10.1111/j.1468-2885.2006.00280.x

Kim, A., Moravec, P. \& Dennis, A. R. (2019). Combating Fake News on Social Media with Source Ratings: The Effects of User and Expert Reputation Rating. Journal of Management Information Systems, 36(3), 31-968 http://dx.doi.org/10.2139/ssrn.3090355

Kovach, B. \& Rosenstiel, T. (2007). The elements of journalism: What newspeople should know and the public should expect. Three Rivers Press. 
Larson, H. J. (2020). Blocking information on Covid-19 can fuel the spread of misinformation. Nature, 580(306). https:// doi.org/10.1038/d41586-020-00920-w

Lázaro-Rodríguez, P. y Herrera-Viedma, E. (2020). “Noticias sobre Covid-19 y 2019$\mathrm{nCoV}$ en medios de comunicación de España: el papel de los medios digitales en tiempos de confinamiento". El profesional de la información, 29(3), e290302. https:// doi.org/10.3145/epi.2020.may.02

López-Borrull, A., Vives-Gràcia, J. y Badell, J.-I. (2018). Fake news, ¿amenaza u oportunidad para los profesionales de la información y la documentación? El

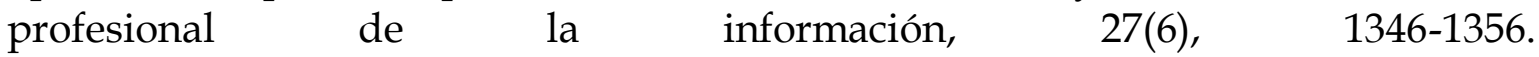
https://doi.org/10.3145/epi.2018.nov.17

Masip, P., Aran-Ramspott, S., Ruiz-Caballero, C., Suau, J., Almenar, E. y PuertasGraell, D. (2020). Consumo informativo y cobertura mediática durante el confinamiento por el Covid-19: sobreinformación, sesgo ideológico y sensacionalismo. El profesional de la información, 29(3), https:// doi.org/10.3145/epi.2020.may.12

Molyneux, L. y Coddington, M. (2019). Aggregation, Clickbait and Their Effect on Perceptions of Journalistic Credibility and Quality. Journal Journalism Practise, 14(4), 429-446. https:// doi.org/10.1080/17512786.2019.1628658

Moreno, Á., Fuentes-Lara, C. \& Navarro, C. (2020). Covid-19 communication management in Spain: Exploring the effect of information-seeking behavior and message reception in public's evaluation. El profesional de la información, 29(4). https://doi.org/10.3145/epi.2020.jul.02

Parra, P. y Oliveira, L. (2018). Fake news: una revisión sistemática de la literatura, (OBS*) Observatorio, 12(5), 54-78. https://doi.org/10.15847/obsOBS12520181374

Posetti, J. y Bontcheva, K. (2020). Deinfodemia. Descifrando la desinformación sobre el COVID-19. Organización de las Naciones Unidas para la Educación, Ciencia y Cultura. https://bit.ly/3aEVfYo

Reig, R. (2000). Medios de comunicación y poder en España. Prensa, radio, televisión y mundo editorial. Paidós.

Reig, R. y Labio, A. (2017). El laberinto mundial de la información. Estructura mediática y poder. Antropos.

Román-San Miguel, A.; Sánchez-Gey, N. y Elías, R. (2020, 10 y 11 de diciembre). Fake news sobre remedios falsos contra el COVID-19 durante el Estado de Alarma. Análisis de los principales periódicos españoles durante la pandemia [ponencia] Congreso Internacional Nodos del Conocimiento 2020. Facultad de Comunicación, Universidad de Sevilla. Sevilla, España. 
Salaverría, R., Buslón, N., López-Pan, F., León, B., López-Goñi, I. Y Erviti, M. C. (2020). Desinformación en tiempos de pandemia: tipología de los bulos sobre la Covid-19. El profesional de la información, 29(3), pp.1-15. https://doi.org/10.3145/epi.2020.may.1

Sánchez-Gey N. (2019). El aumento de las noticias falseadas y sus consecuencias en el que hacer de los profesionales de la información en televisión. Ámbitos. Revista Internacional de Comunicación 159-181. https://doi.org/10.12795/Ambitos.2019.i45.101

Sánchez-Gey, N. (2021). Las dinámicas actuales de los periodistas de investigación y la entrevista periodística. En C. R. Monedero, A. C. Tomás y J. F. Plaza, Aspectos éticos y marcos legales de la comunicación. Tirant Editorial.

Serrano, P. (2010). Traficantes de la información. La historia oculta de los grupos de comunicación españoles. Ediciones Akal.

Shu, K.; Sliva, A; Wang, S.; Tang, J. y Liu, H. (2017). "Fake news detection on social media: a data mining perspective". ACM SIGKDD Explor. Newslett, 19(1), 22-36. https://bit.ly/3euatyg

Silverio Moreno, P. (2018). "El rigor informativo en la era de la posverdad: la amenaza de las fake news en las redes sociales". Comunicación y Hombre, 15, 112. https://bit.ly/36EZxv2

Westlund, O. y Ghersetti, M. (2015). "Modelling news media use. Positing and applying the GC/MC model to the analysis of media use in everyday life and crisis situations". Journalism studies, 16(2), 133-151. https://doi.org/10.1080/1461670X.2013.868139

Zannettou, S.; Sirivianos, M.; Blackburn, J. \& Kourtellis, N. (2019). The Web of False Information: Rumors, Fake News, Hoaxes, Clickbait, and Various Other Shenanigans. Journal of Data and Information Quality. 10, 1-26. https://doi.org/10.1145/3309699

\section{AUTORES:}

\section{Aránzazu Román San Miguel}

Doctora en Periodismo y Experta en Comunicación Institucional y Márketing Político por la Universidad de Sevilla. Actualmente es Profesora Ayudante Doctora en el Departamento de Periodismo II de la Universidad de Sevilla. Asimismo, es ayudante de dirección del Máster en Periodismo Deportivo y ha sido profesora y coordinadora del Máster en Comunicación Institucional y Política de la universidad hispalense. Además es miembro del Grupo de Investigación "Estrategias de Comunicación". Es autora de numerosos libros, capítulos de libros y artículos científicos sobre comunicación y periodismo. 
Orcid ID: https:/ / orcid.org/0000-0002-9131-2629

Google Scholar:

https://scholar.google.com/citations?user=KQIS_z0AAAAJ\&hl=es\&authuser=1

Research ID: https://publons.com/researcher/2279421/aranzazu-arsm-roman-sanmiguel/

Scopus: https://www.scopus.com/authid/detail.uri?authorId $=56041639800$

ResearchGate:

https://www.researchgate.net/profile/Aranzazu_Roman_San_Miguel

Dialnet: https:// dialnet.unirioja.es/servlet/autor?codigo=2598513

\section{Nuria Sánchez-Gey Valenzuela}

Doctora en Comunicación y licenciada en Periodismo por la Universidad de Sevilla. Actualmente trabaja como profesora en el Centro Universitario San Isidoro adscrito a la Universidad Pablo Olavide de Sevilla. Ha colaborado en distintos libros y también ha realizado artículos y ponencias en congresos especializándose en televisión, medios de comunicación, profesión periodística y Estructura de la Información. En el plano profesional, ha sido reportera más de 15 años en diversos medios de comunicación autonómicos y nacionales. Durante tres temporadas en el programa "Equipo de Investigación" de la televisión nacional privada, La Sexta, y antes de esto ha ejercido su labor como reportera en la sección de Actualidad de "La Tarde, aquí y ahora" que se emite a diario en Canal Sur Televisión. Asimismo, durante cuatro años ha trabajado en Informativos Telecinco.

Orcid ID: https:/ / orcid.org/0000-0002-4891-9134

Google Scholar:https://scholar.google.com/citations?user=EclOYpwAAAAJ\&hl=es

\section{Rodrigo Elías Zambrano}

Doctor en Comunicación y Licenciado en Comunicación Audiovisual y Máster en Gestión de Empresas AV por la Universidad de Sevilla, Máster en Comunicación y Educación AV por la Universidad de Huelva y Experto en E-Learning. A nivel docente, ha sido profesor en el Departamento de Marketing y Comunicación de la Universidad de Cádiz siendo, actualmente, Profesor Ayudante Dr. en el área de Publicidad y RR.PP. en la Facultad de Comunicación de la Universidad de Sevilla. Es, además, miembro del Grupo de investigación SEJ420. A nivel profesional, ha estado ligado al mundo de la realización audiovisual y publicitaria para cadenas nacionales como Canal Sur Tv., Tele5 y Antena3 o, a nivel internacional, para RAI, CNBC, Al Jazeera o NHK, entre otras.

Orcid ID: https:// orcid.org/0000-0001-8256-582X.

Google Scholar:

https://scholar.google.es/citations?user=659XcUcAAAAJ\&hl=es\&authuser=1

Researcher ID: https://publons.com/researcher/3426900/rodrigo-elias/ 